\title{
Clinical medication reviews in elderly patients with polypharmacy: a cross-sectional study on drug-related problems in the Netherlands
}

\author{
Sek Hung Chau ${ }^{1}$ Aaltje P. D. Jansen ${ }^{2,3} \cdot$ Peter M. van de Ven ${ }^{4} \cdot$ Petra Hoogland $^{5}$ • \\ Petra J. M. Elders ${ }^{2,3} \cdot$ Jacqueline G. Hugtenburg ${ }^{1,2}$
}

Received: 2 December 2014/Accepted: 21 September 2015/Published online: 23 November 2015

(C) The Author(s) 2015. This article is published with open access at Springerlink.com

\begin{abstract}
Background Knowledge of drug-related problems (DRPs) identified in the medication of home-dwelling elderly patients with polypharmacy has been based predominantly on medication reviews conducted in research settings rather than in daily practice. Objective To evaluate the prevalence of DRPs identified by means of a clinical medication review (CMR) and the implementation rate of proposed interventions in a large group of older patients with polypharmacy in the daily practice of community pharmacies. Setting 318 Dutch community pharmacies. Method A crosssectional study based on CMR-data of 3807 older patients ( $\geq 65$ years) with polypharmacy ( $\geq 5$ drugs) completed between January and August 2012. Data were extracted from community pharmacists' databases and entailed: year of birth, gender, dispensing data, number and nature of identified DRPs, consultations performed, proposed and implemented interventions. Main outcome measure Prevalence of DRPs, drug classes involved in overtreatment and undertreatment, and proposed and implemented interventions. Results A median of two DRPs (interquartile range 1-4; mean 3.0) was
\end{abstract}

Sek Hung Chau

s.chau@vumc.nl

1 Department of Clinical Pharmacology and Pharmacy, VU University Medical Center, De Boelelaan 1117,

1081 HV Amsterdam, The Netherlands

2 The EMGO Institute for Health and Care Research, VU University Medical Center, Amsterdam, The Netherlands

3 Department of General Practice and Elderly Care Medicine, VU University Medical Center, Amsterdam, The Netherlands

4 Department of Epidemiology and Biostatistics, VU University Medical Center, Amsterdam, The Netherlands

5 Department of Pharmaceutical Affairs, Service Apotheek Beheer B.V., Enter, The Netherlands identified per patient. The DRP-categories overtreatment $(25.5 \%)$ and undertreatment (15.9\%) were found most frequently. $46.2 \%$ of the proposed interventions to solve DRPs were implemented as proposed, in $22.4 \%$ of cases, the intervention differed from the proposal. In $31.3 \%$ of cases no intervention was implemented. Conclusion By conducting a CMR community pharmacists identified a median of two DRPs in older patients with polypharmacy. Overtreatment and undertreatment accounted for $41.4 \%$ of the DRPs identified. In dealing with DRPs, pharmacists proposed a variety of interventions of which the majority $(69.9 \%)$ was either implemented or led to alternative interventions. A set of explicit criteria should be applied during a CMR to solve and prevent DRPs.

Keywords Clinical medication reviews - Community pharmacists · Drug-related problems · Netherlands · Older adults Patient care $\cdot$ Pharmaceutical care

\section{Impact of findings on practice}

- Clinical medication reviews routinely conducted by community pharmacists contribute to a reduction of DRPs in the medication of older patients with polypharmacy.

- The application of explicit criteria (STOPP/START or the Amsterdam Tool) in a clinical medication review may be a useful method to identify (potential) DRPs frequently found in the medication of older patients with polypharmacy.

\section{Introduction}

Conducting medication reviews is a method often recommended to identify and solve drug-related problems (DRPs) in order to optimise drug treatment and to improve 
patient health outcomes [1-3]. DRPs can be defined as events involving drug treatment that are actually or potentially harmful to a patient's health or prevent patients to optimally benefit from treatment [4]. The term medication review is used for a broad array of interventions, which are aimed to identify and solve DRPs. A clinical medication review (CMR) entails a review involving communication with the patient while considering treatment in the context of the patient's underlying condition and symptoms [2]. The advantage of patient involvement is the identification of more DRPs and the possibility to identify DRPs which are particularly relevant to the patient and therefore should be tackled with priority [5-8]. The risk of DRPs increases with age, number of diseases and number of drugs prescribed $[9,10]$. Older patients with polypharmacy are most likely to benefit from a medication review $[11,12]$ as they are more vulnerable to complications and admission to hospital caused by DRPs [9]. Knowledge of DRPs identified in home-dwelling older patients with polypharmacy and their origin predominantly has been derived from medication reviews in research settings rather than in daily practice of community pharmacy. Medication reviews conducted in research settings identified 2.5-10 DRPs in older patients with polypharmacy [7, 13, 14]. Differences in the number of identified DRPs can be explained by variations in the target population, experience of the pharmacist conducting the review, extent of patient involvement, access to General Practitioner's (GP) medical records, and patient-related factors such as age, number of diseases, number of drugs, and living conditions (e.g. residential versus home dwelling) [15-17].

Knowledge of the type of DRPs in the elderly identified by means of a CMR has been mainly obtained from studies of 100 up to 400 patients. DRPs most frequently identified relate to drug selection problems $(27.8-42.0 \%)$ [7, 13, 14], over- and underdosing (10.8-30.0\%), and over(9.0-29\%) and undertreatment (3.0-27.9\%) [7, 13, 14, 18, 19]. However, data on DRPs identified by means of a CMR in daily practice is scarce. A study on Australian CMRs conducted by accredited community pharmacists nationwide between 1998 and 2005 in daily practice revealed on mean 4.6 DRPs per patient. DRPs most frequently identified were drug selection problems $(24.9 \%)$, toxicity, adverse reactions and side effects (19.7\%), and undertreatment (15.7\%). Over- and underdosing comprised $8.9 \%$ of the DRPs [17].

A limited number of studies has reported whether and how proposals for interventions forthcoming from CMRs were dealt with, using heterogeneous outcome measures [14, 19-24]. Agreement of the prescriber with the proposal was reported in two studies and amounted to 41.8 and $75.3 \%$ respectively $[19,20]$. Changes observed in clinical or pharmacy records on the basis of CMRs were reported as implementation rates between 17 and $85 \%$ [14, 20-23]. However, as yet data on implementation rates in daily practice are lacking.

In the Netherlands, community pharmacists started to conduct CMRs in older patients with polypharmacy on a large scale as part of the care contractually agreed with health insurers. This enabled the implementation of proposed interventions in daily practice and the current study on DRPs. Standard health insurance is legally compulsory for every person living or working in the Netherlands [25]. Dutch community pharmacies use computerised systems to register dispensed medication which also enables registration of over-the-counter medication [26]. Most patients are registered in a single pharmacy while shopping behaviour (i.e. visiting more than one pharmacy) tends to be low [27]. When a patient visits another pharmacy and patient permission is obtained, the patients' main pharmacy is informed about the dispensed medication and dosing advices, electronically by using a secured connection or by a fax message. Prescribers are also obliged to list the indication when prescribing a drug that appears on a list of 23 selected drugs with a small therapeutic window, and to actively inform pharmacists in the case of an abnormal renal function [28]. This enables community pharmacists to keep medication records complete and detect drug-drug interactions among others. These Dutch requirements are quite unique in comparison with pharmacy practice in other countries [27].

\section{Aim of the study}

The present study aimed to investigate the number of DRPs in the elderly with polypharmacy identified by means of a CMR in daily practice of community pharmacy and the implementation rate of the proposed interventions.

\section{Ethical approval}

Since anonymised data extracted from the community pharmacists' databases were used, ethical approval was not required according to Dutch legislation.

\section{Method}

\section{Design and setting}

A cross-sectional study was carried out based on CMRs in older patients with polypharmacy completed between January and August 2012. Data were acquired from all 318 Dutch community pharmacies affiliated to Nederlandse 
Service Apotheek Beheer (16\% of all community pharmacies), a franchise organisation of independent community pharmacies, located across the Netherlands. Patient characteristics, prevalence of identified DRPs, and proposed and implemented interventions have been registered in a database using the Service Apotheek Medication Review Tool (SAMRT) in NControl, a collection of web applications supporting the process of pharmaceutical care.

\section{Study population}

In 2012 eight Dutch health insurance companies (combined market share $>85 \%$ ) contracted CMRs to be conducted by community pharmacists though imposing different patient criteria for reimbursement. For example, one insurer excluded patients with multidose drug dispensing systems (MDD) from CMR. In MDD, medication are packaged and ordered in separate compartments for each dose occasion and labelled with patient data, date and time of intended intake and drug contents. Other insurers only reimbursed CMRs for patients using specific drug classes such as drugs for COPD or specific combinations of cardiovascular drugs.

However, the CMRs of all patients could be registered in the SAMRT database. From this database, the study population for the current study was composed, consisting of patients aged 65 years or older with polypharmacy. Polypharmacy is defined as the use of at least five drugs indicated for the treatment of a chronic disease at the anatomical therapeutic chemical (ATC)-5 level in the past four months. In case of preparations for sensory organs, only drugs intended for long-term use were included (ATCclass S01E,F,G). Anti-infectives (ATC-class J, G01, S01A,C, S02A,C) are intended for short-term use and therefore have been excluded. Drugs less likely to cause relevant DRPs, such as dermatologicals (ATC-class D) and topical products (ATC-class M02), were also excluded for the calculation of the total number of drugs.

\section{Clinical medication review}

CMRs were conducted by community pharmacists who completed a medication review training accredited by the Royal Dutch Pharmacists Association. Pharmacists followed a method that evolved into the STRIP method [29]. Each CMR started with a semi-structured interview with the patient. In this interview, the aim and use of the patients' medication were discussed as well as any DRP experienced or perceived by the patient. In conducting a CMR pharmacists were supported by the SAMRT. Different pharmacists may have been involved in conducting the CMRs, if multiple pharmacists were employed in a pharmacy. The medication review tool guides the pharmacist through the medication history of the patient to identify possible DRPs. Proposed interventions were discussed with the prescriber, unless the intervention was not regarding a change of medication i.e. repeating an inhaler instruction or creating a dosing schedule. Final proposals to be implemented were discussed with the patient by the pharmacist. Furthermore, SAMRT served as a registration tool to CMR proceedings including a summary of the patient interview, registration of diseases (International Classification for Primary Care, ICPC code), DRPs identified, whether the prescriber and/or patient was consulted to solve the DRP and proposed and implemented interventions.

\section{Data collection}

Data of patients of 65 years and older with polypharmacy were extracted from the community pharmacists' databases (pharmacy information and administration system and SAMRT). Data entailed: year of birth, gender, dispensing data, number and nature of identified DRPs, consultations performed, proposed interventions and those implemented.

\section{Outcome measures and data analysis}

Descriptive analyses were performed on anonymised data of the outcome measures using statistical software (SPSS version 20.0). Characteristics have been presented as number and mean [with standard deviation (SD)]. For variables that were not normally distributed, both the median [with interquartile range (IQR)] and mean is reported in order to be able to compare results with the existing literature. Percentages of drug classes involved in the two largest DRP categories were calculated by dividing the number of DRPs involving the drug class on the total number of DRPs in that category.

\section{Results}

\section{Patient characteristics}

3807 CMRs were conducted in older patients with polypharmacy across 258 of 318 pharmacies. The participating older adults had a mean age of 78 years; $57.9 \%$ were female. Patients used a median of nine drugs (IQR 7-11; mean 9.54) for the treatment of a chronic disease (see Table 1). No patient received more than one CMR.

\section{Number of DRPs and DRP prevalence}

Table 2 lists the number of the various DRPs that were identified. In total, 11,419 DRPs were found in 3807 
Table 1 Patient demographics

\begin{tabular}{ll}
\hline Characteristics & $\begin{array}{l}\text { Total population } \\
\mathrm{n}=3807\end{array}$ \\
\hline $\begin{array}{l}\text { Gender } \\
\text { Male }\end{array}$ & $42.1 \%$ \\
Age (years) & \\
Mean (SD) & $78(7.68)$ \\
Range & $65-102$ \\
Number of chronically used drugs & \\
Median (IQR) & $9(7-11)$ \\
Mean (SD) & $9.54(3.40)$ \\
Range & $5-27$ \\
Number of DRPs & \\
Median (IQR) & $2(1-4)$ \\
Mean (SD) & $3.00(2.26)$ \\
Range & $1-26$
\end{tabular}

$S D$ standard deviation, $I Q R$ interquartile range

Table 2 Number of DRPs per category

\begin{tabular}{|c|c|c|}
\hline DRP categories & $\mathrm{n}$ & $\%$ \\
\hline Overtreatment & 2915 & 25.5 \\
\hline Undertreatment & 1814 & 15.9 \\
\hline Drug not effective & 975 & 8.5 \\
\hline Contra-indication & 971 & 8.5 \\
\hline Side effect & 923 & 8.1 \\
\hline Difficulty using dosage form & 756 & 6.6 \\
\hline Interaction & 664 & 5.8 \\
\hline Non adherence & 645 & 5.6 \\
\hline Dose too low & 622 & 5.4 \\
\hline Dose too high & 568 & 5.0 \\
\hline Inappropriate dosage form & 96 & 0.8 \\
\hline Miscellaneous problem ${ }^{\mathrm{a}}$ & 470 & 4.1 \\
\hline Total DRPs & 11,419 & 100 \\
\hline
\end{tabular}

${ }^{a}$ Besides drug-related problems, the category 'miscellaneous problem' also contained non-drug-related problems, for example, lifestyle advice given such as smoking cessation

patients. A median of two (IQR 1-4) DRPs was found per patient (mean: 3.0). Overtreatment $(25.5 \%)$ and undertreatment $(15.9 \%)$ were the most common DRPs. Other DRP-categories each contributed $5.0-8.5 \%$ to the total number of DRPs reported. Inappropriate dosage form was the least common DRP $(0.8 \%)$.

\section{Drug classes involved in overtreatment and undertreatment}

Drug classes involved in the DRP categories overtreatment and undertreatment have been listed in Table 3. Drug classes most frequently involved in overtreatment are drugs for peptic ulcer and gastro-oesophageal reflux disease (GORD, $10.2 \%$ ), antithrombotic agents $(6.7 \%)$ and lipid modifying agents $(5.2 \%)$.

The majority of the drugs for peptic ulcer and GORD involved in overtreatment were proton-pump inhibitors [PPI, $\quad(n=281,94.9 \%)$ ]. PPIs were classified as overtreatment because there was no clear indication or gastroprotective medication was no longer needed since a non-steroidal anti-inflammatory drug (incl. acetylsalicylic acid) or selective serotonin reuptake inhibitor was stopped previously. Vitamin $K$ antagonists $(n=47)$ were regarded as overtreatment because the indication was unclear or unknown to the patient and pharmacist. However, after consultation with the prescriber, these drugs frequently turned out to be indicated. In most cases clopidogrel was registered as overtreatment $(n=38)$, mainly because the patient had used it longer than 1 year and treatment could be discontinued according to the current medical guidelines. Rosuvastatin contributed $50.3 \%(\mathrm{n}=77)$ to the group of lipid modifying agents. Lipid modifying agents and antithrombotic agents were also involved in undertreatment, 2.9 and $2.6 \%$ respectively, followed by vitamin $\mathrm{A}$ and/or D (2.5\%).

\section{Interventions}

Proposed interventions have been listed in Table 4. Stopping to use a drug was suggested most frequently (19.6\%), second most suggested was monitoring of the patient $(18.4 \%)$, e.g. measuring of the blood pressure or performing a blood test. $46.2 \%$ of the interventions were implemented as proposed. In $22.4 \%$ of the cases, the intervention effectuated differed from the proposal and in $31.3 \%$ of the cases, no intervention was performed. Reasons for not implementing an intervention included a rejection by the prescriber $(27.5 \%)$ or patient $(11.9 \%)$; and correction of the DRP in the time between the patient interview and the consultation with the physician (mostly a GP) or patient $(13.1 \%)$. Some interventions were not implemented immediately, but instead the patient was monitored to decide whether the intervention was indicated at a later moment $(26.2 \%)$. An overview of all interventions effectuated can be found in Table 5 .

\section{Discussion}

The objective of this study was to investigate the number and nature of DRPs identified by means of a community pharmacist-conducted CMR in 3807 older patients with polypharmacy in daily practice. The implementation rate of interventions proposed to solve DRP was also investigated. 
Table 3 Drug classes involved in DRP categories overtreatment and undertreatment

\begin{tabular}{|c|c|c|c|}
\hline & & $\mathrm{n}$ & Percentage $(\%)$ \\
\hline \multicolumn{4}{|c|}{ Drug classes involved in overtreatment } \\
\hline $\mathrm{A} 02 \mathrm{~B}$ & Drugs for peptic ulcer and GORD & 296 & 10.2 \\
\hline B01A & Antithrombotic agents & 195 & 6.7 \\
\hline C10A & Lipid modifying agents & 153 & 5.2 \\
\hline $\mathrm{A} 06 \mathrm{~A}$ & Drugs for constipation & 103 & 3.5 \\
\hline N05B & Anxiolytics & 83 & 2.8 \\
\hline N05C & Hypnotics and sedatives & 75 & 2.6 \\
\hline N06A & Antidepressants & 71 & 2.4 \\
\hline $\mathrm{C} 03 \mathrm{C}$ & High-ceiling diuretics & 66 & 2.3 \\
\hline C07A & Beta blocking agents & 60 & 2.1 \\
\hline N02B & Other analgesics and antipyretics & 60 & 2.1 \\
\hline \multicolumn{4}{|c|}{ Drug classes involved in undertreatment } \\
\hline C10A & Lipid modifying agents & 53 & 2.9 \\
\hline B01A & Antithrombotic agents & 48 & 2.6 \\
\hline A11C & Vitamin A and/or D & 46 & 2.5 \\
\hline A12A & Calcium & 26 & 1.4 \\
\hline $\mathrm{A} 10 \mathrm{~B}$ & Blood glucose lowering drugs, excl. insulin & 23 & 1.3 \\
\hline A02B & Drugs for peptic ulcer and GORD & 17 & 0.9 \\
\hline C01D & Vasodilators used in cardiac diseases & 15 & 0.8 \\
\hline M05B & Drugs affecting bone structure and mineralisation & 15 & 0.8 \\
\hline C09A & ACE inhibitors & 14 & 0.8 \\
\hline C07A & Beta blocking agents & 11 & 0.6 \\
\hline
\end{tabular}

Percentage given is the percentage of a drug class reported in the DRP category. GORD gastro-oesophageal reflux disease

Table 4 Prevalence and type of proposed interventions after identification of the DRP by pharmacists

\begin{tabular}{lcclll}
\hline & Number & Percentage $(\%)$ & Implemented (\%) & Other intervention (\%) & No intervention $(\%)$ \\
\hline Stop drug & 2238 & 19.6 & 46.6 & 21.4 & 32.0 \\
Provide monitoring & 2099 & 18.4 & 52.8 & 23.1 & 24.1 \\
Adjust dose & 1684 & 14.7 & 43.3 & 25.1 & 31.6 \\
Add drug & 1601 & 14.0 & 36.3 & 27.4 & 36.3 \\
Switch drug & 1307 & 11.5 & 38.5 & 26.0 & 35.5 \\
Provide education & 1225 & 10.7 & 67.9 & 12.3 & 19.8 \\
Synchronise medication & 304 & 2.7 & 82.6 & 12.5 & 4.9 \\
Switch dose form & 176 & 1.5 & 60.2 & 24.4 & 15.4 \\
Other & 766 & 6.7 & 15.5 & 21.5 & 63.0 \\
Total & 11,419 & 100.0 & $46.2^{\mathrm{a}}$ & $22.4^{\mathrm{a}}$ & $31.3^{\mathrm{a}}$ \\
\end{tabular}

a These percentages were calculated based on the known outcomes $(11,400)$ as a proportion of the total interventions $(11,419)$. $0.2 \%$ of the interventions $(\mathrm{n}=19)$ was not attributed to a specific category

In older patients with polypharmacy whose medication was evaluated by means of a CMR three DRPs were identified on mean. This number is on the lower end of the range of 2.5-10 DRPs found for these patients in research settings $[7,13,14]$ and comparable with the 4.6 DRPs previously found in daily practice [17]. However, comparison is problematic as DRPs are not normally distributed, but skewed to the right. Future studies should report median and IQR to allow better inter-study comparisons of the number of DRPs.

Overtreatment (25\%) was the most frequently identified DRP. The prevalence of overtreatment was within the range found in research settings (15.7-29\%) [7, 13, 14, $18]$. Other studies also showed that cessation of medication 
Table 5 Distribution of interventions implemented after identification of the DRP

\begin{tabular}{lc}
\hline & Percentage $(\%)$ \\
\hline Information/advice given & 17.3 \\
Research conducted & 14.6 \\
Drug stopped & 11.2 \\
Dose changed/adjusted & 7.9 \\
Drug started & 5.8 \\
Drug replaced & 5.5 \\
Medication synchronised & 2.4 \\
Dosage form changed & 1.1 \\
Other/unspecified & 4.2 \\
No intervention & 30.1 \\
Total & 100.0 \\
\hline
\end{tabular}

was the most common recommendation following a CMR. In this respect, it should be noted that the past decade attention for the deprescribing of superfluous drug has increased [30]. Undertreatment $(16 \%)$ was the second most frequently identified DRP. This percentage is similar to that found in a previous study on CMRs in daily practice $(15.7 \%)$ [17] and also within the range obtained in research settings (3.0-27.9\%) [7, 13, 14, 18, 19]. Overtreatment and undertreatment accounted for $41.4 \%$ of the DRPs identified. This implicates that explicit criteria developed for the detection of potentially inappropriate drugs and potentially omitted beneficial drugs, such as the STOPP/START criteria may be useful during a CMR as a tool to systematically screen the medication of the patient. However, rather than overtreatment and undertreatment, a larger part of DRPs concerned other DRPs (i.e. drug not effective, side effect, difficulty using dosage form). For additional support of the CMR process, explicit criteria addressing these DRPs may be useful, for example by using the recently developed Amsterdam Tool [31].

Drugs for peptic ulcer and GORD, antithrombotic agents and lipid modifying agents were most frequently involved in overtreatment. It is known that in some cases, drugs for peptic ulcer and GORD are used longer than indicated for GORD [32, 33] or gastroprotection. The unnecessary use of gastroprotective medication in some cases may be explained by the continuation of gastroprotective medication after the gastric problem enhancing drug was discontinued. Lipid modifying agents and antithrombotic agents were also frequently involved in overtreatment, as well as undertreatment. This could be explained by the fact that some patients with an indication are not treated, while others may receive a more potent drug than necessary (e.g. rosuvastatin while simvastatin has not been tried first). Drug classes used more often may have resulted in a higher percentage in a DRP-category. However, this still provides important information. By giving more attention to these drug classes, which caused a large number of DRPs, the number of DRPs may decrease.

Nearly half $(46.2 \%)$ of all pharmacist-proposed interventions were implemented as proposed. Furthermore, in an additional $23.7 \%$ of cases, DRPs were dealt with in a manner different from the adjustment initially proposed. Apparently, discussion with GPs and patients in the CMR process influenced the choice of interventions and resulted in different adjustments. In research settings, implementation rates between 17 and $85 \%$ were found [14, 19-24] and implementation rates were found to be generally higher when pharmacists had more clinical experience, had access to GP medical records and when a patient interview was part of the review process [34]. Higher implementation rates have also been found in studies focussing on selected DRPs [19] or in studies in which only a limited number of interventions were proposed [22]. Some of these factors may have had an effect on the implementation rate in the present study. The pharmacists in the present study proposed many interventions on a wide range of DRPs. This may have had a negative effect on the implementation rate whereas the patient interview may have had a positive effect. Although community pharmacists were specifically trained to conduct CMRs, it is likely that some community pharmacists still had limited experience in conducting CMRs, largely because in the Netherlands routinely conducted CMR were only reimbursed from 2012 on a larger scale. Finally, for effectively addressing DRPs, close cooperation with the GP seems important [34]. Unfortunately, there were no data providing information to what extent this cooperation was practised.

To appreciate the findings of the present study some points that may have affected the results must be addressed. First, the SAMRT has been designed to support pharmacists in conducting CMR in a structured manner on a routine basis, not as a registration system for research purposes. This might have resulted in a registration bias, due to variability in the registration of DRPs which in turn would have affected the findings on number and nature of DRPs and implementation rates. However, arguing against this potential bias as well as being a strength of this study, is that all pharmacists completed the same training and used the same SAMRT tool. Second, requirements for CMR reimbursement of pharmacists by the health insurers involved led to some heterogeneity in the patient population. Regarding the exclusion of patients using a MDD: this might have led to a lower number of DRPs, because patients using MDD are known to have more DRPs [35]. Some insurers only reimburse CMRs for patients using specific drug classes such as drugs for COPD or specific combinations of cardiovascular drugs, which might have influenced the number of DRPs. Pharmacists may also have selected those patients who they assumed to benefit the 
most, i.e. are more likely to suffer from DRPs, which might have increased the number of DRPs. On the other hand, other pharmacists may have approached all eligible patients until they met the number of CMRs they contractually agreed to conduct, which might have influenced the number of DRPs as the selection was more random, i.e. also patients with less DRPs. To what extent these issues affected the findings overall, cannot be determined. Third, the experience of the pharmacists has not been taken into account. Although all pharmacists were trained to conduct CMRs in the same fashion, this may have influenced the number of DRPs identified and the percentage of interventions implemented. Nevertheless, since this was a crosssectional sample, it may be regarded as representative of trained community pharmacists with varying experience with conducting CMRs.

\section{Conclusion}

In the present study, conducted in daily practice, community pharmacists identified on mean three DRPs as the result of a CMR in older patients with polypharmacy. This number is similar to that of previous studies predominantly conducted in a research setting. Overtreatment and undertreatment accounted for less than half of the DRPs identified $(41.4 \%)$. More attention for drug classes regularly involved with DRPs may further decrease the number of DRPs. In dealing with DRPs, pharmacists proposed a variety of interventions of which the majority (69.9\%) was either implemented or led to alternative interventions. The application of explicit criteria (STOPP/START or the Amsterdam Tool) in a CMR may be useful in addressing and preventing DRPs frequently found in the medication of older patients with polypharmacy.

Acknowledgments The authors would like to thank Dr. J.J. Beckeringh and Prof. Dr. F.G. Schellevis M.D. Ph.D. for their contribution on the writing of this manuscript.

Funding For the data analysis, an unrestricted grant has been received from Service Apotheek Beheer B.V.

Conflicts of interest P.H. is an employee of Service Apotheek Beheer B.V. However, the funding body had no role in the analysis nor interpretation of the findings of this article. Other authors declare no conflict of interest.

Open Access This article is distributed under the terms of the Creative Commons Attribution 4.0 International License (http://crea tivecommons.org/licenses/by/4.0/), which permits unrestricted use, distribution, and reproduction in any medium, provided you give appropriate credit to the original author(s) and the source, provide a link to the Creative Commons license, and indicate if changes were made.

\section{References}

1. Nederlands Huisartsen Genootschap [Dutch College of General Practitioners]. Multidisciplinaire Richtlijn Polyfarmacie bij ouderen 2012 [Multidisciplinary Directive Polypharmacy in the elderly 2012]. Utrecht: Nederlands Huisartsen Genootschap; 2012. Dutch.

2. Clyne W, Blenkinsopp A, Seal R. A Guide to Medication Review [Internet]. Liverpool: The National Prescribing Center; 2008 [cited 2014 Jan 7]. Available from: http://www.npc.nhs.uk/ review_medicines/intro/resources/agtmr_web1.pdf.

3. Pharmaceutical Society of Australia Ltd. Guidelines for pharmacists providing Home Medicines Review (HMR) services [Internet]. Pharmaceutical Society of Australia Ltd; 2011 [cited 2014 Jan 7]. Available from: http://www.psa.org.au/download/ practice-guidelines/home-medicines-reviewservices.pdf.

4. Schaefer M. Discussing basic principles for a coding system of drug-related problems: the case of PI-Doc. Pharm World Sci. 2002;24(4):120-7.

5. Lowe CJ, Petty DR, Zermansky AG, Raynor DK. Development of a method for clinical medication review by a pharmacist in general practice. Pharm World Sci. 2000;22(4):121-6.

6. Blenkinsopp A, Bond C, Raynor DK. Medication reviews. Br J Clin Pharmacol. 2012;74(4):573-80.

7. Kwint HF, Faber A, Gussekloo J, Bouvy ML. The contribution of patient interviews to the identification of drug-related problems in home medication review. J Clin Pharm Ther. 2012;37(6):674-80.

8. Krska J, Cromarty JA, Arris F, Jamieson D, Hansford D, Duffus PR, et al. Pharmacist-led medication review in patients over 65: a randomized, controlled trial in primary care. Age Ageing. 2001;30(3):205-11.

9. Leendertse AJ, Egberts ACG, Stoker LJ, van den Bemt PMLA, HARM Study Group. Frequency of and risk factors for preventable medication-related hospital admissions in the Netherlands. Arch Intern Med. 2008;168(17):1890-6.

10. Simonson W, Feinberg JL. Medication-related problems in the elderly: defining the issues and identifying solutions. Drugs Aging. 2005;22(7):559-69.

11. De Smet PAGM, HARM-Wrestling Group. Hospital admissions related to medications and implementing guidelines. Arch Intern Med. 2009;169(8):810-1 (author reply 811).

12. Warlé-van Herwaarden MF, Kramers C, Sturkenboom MC, van den Bemt PMLA, De Smet PAGM, Dutch HARM-Wrestling Task Force. Targeting outpatient drug safety: recommendations of the Dutch HARM-Wrestling Task Force. Drug Saf. 2012;35(3):245-59.

13. Milos V, Rekman E, Bondesson Å, Eriksson T, Jakobsson U, Westerlund $\mathrm{T}$, et al. Improving the quality of pharmacotherapy in elderly primary care patients through medication reviews: a randomised controlled study. Drugs Aging. 2013;30(4):235-46.

14. Kwint HF, Faber A, Gussekloo J, Bouvy ML. Effects of medication review on drug-related problems in patients using automated drug-dispensing systems: a pragmatic randomized controlled study. Drugs Aging. 2011;28(4):305-14.

15. Laaksonen R, Duggan C, Bates I. Performance of community pharmacists in providing clinical medication reviews. Ann Pharmacother. 2010;44(7-8):1181-90.

16. Kwint HF, Faber A, Gussekloo J, Bouvy ML. Completeness of medication reviews provided by community pharmacists. J Clin Pharm Ther. 2014;39(3):248-52.

17. Stafford AC, Tenni PC, Peterson GM, Jackson SL, Hejlesen A, Villesen C, et al. Drug-related problems identified in medication reviews by Australian pharmacists. Pharm World Sci. 2009;31(2):216-23. 
18. Elliott RA, Woodward MC. Medication-related problems in patients referred to aged care and memory clinics at a tertiary care hospital. Australas J Ageing. 2011;30(3):124-9.

19. Sellors J, Kaczorowski J, Sellors C, Dolovich L, Woodward C, Willan A, et al. A randomized controlled trial of a pharmacist consultation program for family physicians and their elderly patients. CMAJ. 2003;169(1):17-22.

20. Vinks THAM, Egberts TCG, de Lange TM, de Koning FHP. Pharmacist-based medication review reduces potential drug-related problems in the elderly: the SMOG controlled trial. Drugs Aging. 2009;26(2):123-33.

21. Denneboom W, Dautzenberg MGH, Grol R, De Smet PAGM. Treatment reviews of older people on polypharmacy in primary care: cluster controlled trial comparing two approaches. Br J Gen Pract. 2007;57(542):723-31.

22. Lenaghan E, Holland R, Brooks A. Home-based medication review in a high risk elderly population in primary care - the POLYMED randomised controlled trial. Age Ageing. 2007;36(3):292-7.

23. Grymonpre RE, Williamson DA, Montgomery PR. Impact of a pharmaceutical care model for non-institutionalised elderly: results of a randomised, controlled trial. Int $\mathrm{J}$ Pharm Pract. 2001;9(4):235-41.

24. Allard J, Hébert R, Rioux M, Asselin J, Voyer L. Efficacy of a clinical medication review on the number of potentially inappropriate prescriptions prescribed for community-dwelling elderly people. CMAJ. 2001;164(9):1291-6.

25. Ministerie van Volksgezondheid, Welzijn en Sport [Ministry of Health, Welfare and Sport]. Wet van 16 juni 2005, houdende regeling van een sociale verzekering voor geneeskundige zorg ten behoeve van de gehele bevolking (Zorgverzekeringswet) [Regulation on the Social Insurance for Medical Care for the Entire Population (Health Insurance Act)]. Staatsblad van het Koninkrijk der Nederlanden 2005;358. Dutch.

26. Monster TBM, Janssen WMT, de Jong PE, de Jong-van den Berg LTW, PREVEND Study Group Prevention of REnal and Vascular ENT Stage Disease. Pharmacy data in epidemiological studies: an easy to obtain and reliable tool. Pharmacoepidemiol Drug Saf. 2002;11(5):379-84.

27. Buurma H, Bouvy ML, De Smet PAGM, Floor-Schreudering A, Leufkens HGM, Egberts ACG. Prevalence and determinants of pharmacy shopping behaviour. J Clin Pharm Ther. 2008;33(1):17-23.

28. Ministerie van Volksgezondheid, Welzijn en Sport [Ministry of Health, Welfare and Sport]. Regeling van de Minister van Volksgezondheid, Welzijn en Sport van 2 juli 2013 (kenmerk 125176-105466-GMT), houdende wijziging van de Regeling Geneesmiddelenwet betreffende de uitwisseling van laboratoriumgegevens en de vermelding van de redden van voorschrijven. [Amendment on the Medicines Act on the exchange of laboratory data and stating the reason for prescribing.] Staatscourant 2013;18918. Dutch.

29. Keijsers CJPW, van Doorn ABD, van Kalles A, de Wildt DJ, Brouwers JRBJ, van de Kamp HJ, et al. Structured pharmaceutical analysis of the systematic tool to reduce inappropriate prescribing is an effective method for final-year medical students to improve polypharmacy skills: a randomized controlled trial. J Am Geriatr Soc. 2014;62(7):1353-9.

30. Reeve E, Shakib S, Hendrix I, Roberts MS, Wiese MD. Review of deprescribing processes and development of an evidencebased, patient-centred deprescribing process. Br J Clin Pharmacol. 2014;78(4):738-47.

31. Mast R, Ahmad A, Hoogenboom SC, Cambach W, Elders PJ, Nijpels G, Hugtenburg JG. Amsterdam tool for clinical medication review: development and testing of a comprehensive tool for pharmacists and general practitioners. BMC Res Notes. 2015; $8: 642$.

32. Lee TJ, Fennerty MB, Howden CW. Systematic review: Is there excessive use of proton pump inhibitors in gastro-oesophageal reflux disease? Aliment Pharmacol Ther. 2004;20(11-12): 1241-51.

33. Forgacs I, Loganayagam A. Overprescribing proton pump inhibitors. BMJ. 2008;336(7634):2-3.

34. Kwint H-F, Bermingham L, Faber A, Gussekloo J, Bouvy ML. The relationship between the extent of collaboration of general practitioners and pharmacists and the implementation of recommendations arising from medication review: a systematic review. Drugs Aging. 2013;30(2):91-102.

35. KNMP [Royal Dutch Pharmacists Association]. KNMP-richtlijn Zorg voor patiënten met geneesmiddelen in een geïndividualiseerde distributievorm [KNMP-directive Care for patients with drugs in a multidose drug dispensing system]; 2013. Dutch. 